\title{
Cooperativismo, autonomía y poder: el movimiento cooperativista en México durante el cardenismo
}

\author{
Eduardo Nava-Hernández ${ }^{\star}$ Beny Oliver Barajas-Pérez ${ }^{\star *}$
}

\footnotetext{
Doctor en Ciencia Política. Profesor e investigador de tiempo completo, Universidad Michoacana de San Nicolás de Hidalgo, Michoacán, México. Correo electrónico: nheduardo@fevaq.net

** Magíster en Ciencias en Desarrollo Local. Profesor investigador, Universidad Michoacana de San Nicolás de Hidalgo, Michoacán, México. Correo electrónico: beny_barajas@fevaq.net
}

Recibido: 1 de marzo del 2015 Aprobado: 30 de abril del 2015

Cómo citar este artículo: Nava-Hernández, E. y Barajas-Pérez, B. O. (2015). Cooperativismo, autonomía y poder: el movimiento cooperativista en México durante el cardenismo. Cooperativismo \& Desarrollo, 23(106), 25-34. doi: http://dx.doi. org/10.16925/co.v23i106.1128

\section{Resumen}

Propósito: exponer y reflexionar críticamente acerca de cuál fue el papel del movimiento cooperativista en México durante el gobierno del general Lázaro Cárdenas del Río y su relación con este. Descripción: se revisan los antecedentes del cooperativismo desde la Revolución mexicana y su uso fundamentalmente político en torno al nuevo régimen; se presenta un análisis exploratorio del proyecto cooperativista bajo el cardenismo. Punto de vista: se recupera el tema político del cooperativismo como instrumento de hegemonía del nuevo régimen y cómo este impactó sobre los trabajadores del cooperativismo; asimismo, cómo se diluyó para estos la posibilidad de asumir la conducción social y la de integrarse a la alianza dominante en la etapa desarrollista y en el periodo actual de reestructuración capitalista. Conclusiones: la experiencia del movimiento cooperativista en el cardenismo muestra la necesidad de contextualizar social e históricamente su acción para trazar sus objetivos y estrategias en cada periodo. El cooperativismo mexicano durante los años veinte y treinta del siglo $\mathrm{xx}$ pone en evidencia cómo la obtención de ventajas y avances inmediatos puede representar un pacto de compromiso inconveniente a la larga para la autonomía del movimiento cooperativista, sobre todo, si ese desarrollismo llega a su fin.

Palabras clave: cardenismo, cooperativismo, hegemonía capitalista, México. 


\title{
Cooperativism, Autonomy and Power: The Cooperative Movement in Mexico during Cardenism
}

\begin{abstract}
Purpose: To expound and critically reflect upon the role of the cooperative movement in Mexico during the administration of General Lázaro Cárdenas del Río and his relationship with that movement. Description: The precedents for cooperativism arise starting with the Mexican Revolution and its fundamentally political use around the new regime; an exploratory analysis is presented of the cooperative project under Cardenism. Point of view: The political topic of cooperativism is reexamined as an instrument of hegemony of the new regime and how this had impacts on the workers of cooperativism; also the way in which the possibility of acquiring social leadership and becoming part of the dominant alliance during the developmental stage and in the current period of capitalist restructuring was diluted. Conclusions: The experience of the cooperative movement during Cardenism shows the need to socially and historically contextualize its action to determine its objectives and strategies in each period. Mexican cooperativism during the 1920s and 1930s shows how obtaining immediate advantages and advances can signify an inconvenient commitment in the long run for the autonomy of the cooperative movement, above all, if that development comes to an end.
\end{abstract}

Keywords: Cardenism, cooperativism, capitalist hegemony, Mexico.

\section{Cooperativismo, autonomia e poder: o movimento cooperativista no México durante o cardenismo}

\section{Resumo}

Propósito: expor e refletir criticamente sobre qual foi o papel do movimento cooperativista no México durante o governo do General Lázaro Cárdenas del Río e sua relação com ele. Descrição: revisam-se os antecedentes do cooperativismo a partir da Revolução Mexicana e seu uso fundamentalmente político em torno do novo regime; apresenta-se uma análise exploratória do projeto cooperativista sob o cardenismo. Ponto de vista: recupera-se o tema político do cooperativismo como instrumento de hegemonia do novo regime e como esta impactou os trabalhadores do cooperativismo; além disso, como se diluiu para estes a possibilidade de assumir a condução social e a de se integrar à aliança dominante na etapa desenvolvimentista e no período atual de reestruturação capitalista. Conclusões: a experiência do movimento cooperativista no cardenismo mostra a necessidade de contextualizar social e historicamente sua ação para traçar seus objetivos e estratégias em cada período. O cooperativismo mexicano durante os anos 1920 e 30 evidencia como a obtenção de vantagens e avanços imediatos pode representar um pacto de compromisso inconveniente em longo prazo para a autonomia do movimento cooperativista, principalmente, se esse desenvolvimentismo chega a seu final.

Palavras-chave: cardenismo, cooperativismo, hegemonia capitalista, México. 


\section{Introducción}

Es una idea aceptada de manera general que el cooperativismo en México vivió una época dorada en la etapa posrevolucionaria, desde el gobierno de Álvaro Obregón (1920-1924) —cuando el Partido Cooperatista de Jorge Prieto Laurens alcanzó diversas posiciones electorales en el Congreso y en gobiernos locales - hasta el periodo de Lázaro Cárdenas (19341940). En esas dos décadas el cooperativismo social o político no solo ganó espacios de representación por elección, sino que también creció como movimiento de manera inusitada, incidió fuertemente en la política social de los gobiernos e impulsó en 1927 la primera Ley General de Sociedades Cooperativas. También se conformaron la Confederación Nacional de Sociedades Cooperativas Socialistas (CNSCS), en 1925, y la Confederación Nacional Cooperativa (CNC), en 1927. En 1929 se realizó en Tampico el Primer Congreso de Sociedades Cooperativas con asistencia de 500 delegados de diversos lugares del país. En 1933, el presidente Abelardo Rodríguez promulgó una segunda Ley de Sociedades Cooperativas y, ya bajo el cardenismo, en 1938, se emitió una tercera, la de más larga vigencia, pues duró hasta 1994.

Todo ello habla de la importancia que el movimiento cooperativo alcanzó con la lucha revolucionaria y el régimen derivado de esta, el cual asumió en gran medida el discurso cooperativista como una alternativa al capitalismo ultraliberal del porfiriato con su marca de desigualdad y miseria para las masas trabajadoras. Pero también esa etapa muestra con tintes de gran claridad las paradojas y tensiones, no siempre reconocidas, contenidas en la relación entre el cooperativismo y los poderes públicos. Producto al mismo tiempo de la movilización de los actores cooperativistas y de la coyuntura que se abrió en el periodo de entreguerras - caracterizado en México como la etapa de la posrevolución-, el auge cooperativo condujo a definiciones clave para el propio movimiento y para el mismo régimen.

\section{Antecedentes: las cooperativas y el estado revolucionario}

Durante la lucha revolucionaria el cooperativismo no parece haber desempeñado un papel muy relevante. En 1915, a instancias del gobierno de Venustiano Carranza y con financiamiento oficial, se creó en Ciudad de México la Sociedad Nacional de Consumo, inspirada en los ideales del cooperativismo, como un recurso contra la especulación y la carestía de los productos básicos. Sin embargo, poco tiempo después el propio Carranza, por falta de recursos para capitalizarla o por la presión de los comerciantes y especuladores, decidió disolverla (Rojas-Coria, 1984, pp. 376-377). Prevalecía más bien el ascenso de los trabajadores organizados en los sindicatos de la Casa del Obrero Mundial (fundada en 1912 bajo el breve gobierno de Francisco I. Madero), que en febrero de ese año firmaron un pacto con el Ejército Constitucionalista para integrar los célebres Batallones Rojos.

Ya derrotada la huelga general de julio-agosto de 1916 que esos mismos sindicatos impulsaron, el carrancismo procedió a la redacción de una nueva Constitución. El artículo 28 contempló la existencia de las sociedades cooperativas de producción, mas sometiéndolas a una rigurosa vigilancia y aun a control por parte del Estado. Dicho artículo indicaba que:

[...] Tampoco constituyen monopolios las asociaciones o sociedades cooperativas de productores que, en defensa de sus intereses o del interés general, vendan directamente a los mercados extranjeros los productos nacionales o industriales que sean la principal fuente de riqueza de la región en que se produzcan, y que no sean artículos de primera necesidad, siempre que dichas asociaciones estén bajo la vigilancia o amparo del Gobierno Federal o de los estados, y previa autorización que al efecto se obtenga de las legislaturas respectivas en cada caso. Las mismas legislaturas, por si o a propuesta del Ejecutivo, podrán derogar, cuando las necesidades públicas así lo exijan, las autorizaciones concedidas para la formación de las asociaciones de que se trata (citado en Contreras y Tamayo, 1983, p. 269; la cursiva es añadida).

El artículo 123, por otra parte, consideraba como de utilidad social a las cooperativas constructoras de vivienda obrera. Ninguna mención adicional se hizo en el nuevo texto constitucional a las cooperativas de producción, de consumo o de crédito, pese a la atención que en ese y otros artículos se daba a la cuestión social.

El auge del cooperativismo político se da bajo el gobierno de Álvaro Obregón, con el ascenso del Partido Cooperatista Nacional. Este fue fundado en 1917 no por verdaderos cooperativistas sino por un conjunto de intelectuales que convocaron a la asamblea constitutiva a "obreros textiles, tranviarios, choferes, 
ferroviarios, profesores y estudiantes" (Rojas-Coria, 1983, p. 378), y a los que más adelante se sumaron periodistas y personajes políticos y militares. En 1920 el PCN adhirió a la candidatura de Obregón, hecho que, con el triunfo de la insurrección de Agua Prieta (abril-mayo de 1920) y la instalación del gobierno obregonista, le abrió la puerta para alcanzar en el Congreso 60 diputaciones y algunos senadores, cinco gubernaturas y casi todos los ayuntamientos del Distrito Federal, así como para tener una influencia importante en el gobierno obregonista (Rojas-Coria, 1983, p. 379; Martínez-Ramírez y Rojas-Herrera, 2003). Su crisis sobrevino, sin embargo, a fines de 1923, cuando los cooperatistas decidieron apoyar la candidatura y posteriormente el levantamiento de Adolfo de la Huerta, opositor al candidato obregonista Plutarco Elías Calles. Difícilmente se puede aceptar, sin embargo, que su derrota fuera un verdadero golpe al movimiento cooperativista como tal, débil a pesar del ascenso político de sus supuestos representantes.

El impulso al movimiento provino, en cambio desde el gobierno de Calles, el nuevo presidente. Este, después de conocer el libro La cooperación del licenciado Luis Gorozpe, le encargó al autor la elaboración del Manual para los fundadores y administradores de cooperativas en México, del que se hizo un tiraje de 50 mil ejemplares (Rojas-Coria, 1983). Entusiasmado por hallar en los ideales cooperativistas una vía para la renovación de los ideales de la Revolución, Calles expidió la primera Ley General de Sociedades Cooperativas, ya mencionada, que comprendía a las sociedades agrícolas, industriales y de consumo, pero no a las de crédito. Trataba a los socios como accionistas, siguiendo la lógica del antiguo Código de Comercio porfirista, que había reconocido a las sociedades por acciones, y remitía a este la reglamentación de sus principales facultades financieras. MartínezRamírez y Rojas-Herrera (2003, p. 395) consideran que esta ley:

Tuvo el inconveniente de no establecer una clara distinción entre las sociedades mercantiles y las organizaciones sin fines de lucro, constituyéndose en una especie de híbrido extremadamente complejo que muy poco contribuyó a distinguir la sociedad cooperativa de otras formas de organización social para la producción.
Pero esta ley, además, sentó las bases para el control estatal sobre las empresas cooperativas al establecer el registro público y otorgarles facultades a las secretarías de Agricultura y de Industria, Comercio y Trabajo para condicionar su reconocimiento, y al someterlas a la fiscalización de estas y aun de la Comisión Nacional Bancaria (Rojas-Coria, 1983).

No obstante las limitaciones de la legislación, el cooperativismo avanzó en ese periodo con la formación de la Confederación Nacional Cooperativa y con organizaciones como el Gremio Unido de Alijadores de Tampico, s. C. L. que, pese al asesinato de su dirigente Isauro Alfaro en abril de 1929, fue el puntal del Primer Congreso Nacional de Sociedades Cooperativas en octubre de ese año, inaugurado con la presencia del presidente Emilio Portes Gil. El Congreso se trazó un programa sobre todo organizativo que pugnaba por fortalecer el papel de las sociedades cooperativas a través de la creación del Departamento de Fomento Cooperativo y del Consejo Técnico de Cooperativas, además de la reforma a la ley de 1927 y la creación de un banco cooperativo refaccionario para apoyar financieramente a las cooperativas existentes y crear otras nuevas.

A raíz del congreso de Tampico se instituyó en 1930 el Departamento de Fomento Cooperativo en la Secretaría de Economía; un año antes se había creado la Escuela de Cooperativismo. Y en la Secretaría de Educación Pública se instituye en 1930 la Dirección Nacional de Cooperativismo. La Escuela de Cooperativismo fue cancelada en 1932 por el nuevo secretario de Educación, Narciso Bassols, quien consideraba que "el cooperativismo aburguesaba a las gentes y les quitaba la preocupación de la revolución social" (Rojas-Coria, 1983, pp. 424-425, 429, 465; Martínez-Ramírez y Rojas-Herrera, 2003, p. 204).

En 1931, el oficialista Partido Nacional Revo lucionario (PNR) funda su propia Escuela Técnica Cooperativista. Pero, lo que es más importante, la CNC logró la promulgación por el presidente Abelardo Rodríguez de una nueva Ley de Sociedades Cooperativas, que representó, en relación con la de 1927, un avance importante por su mayor apego a los principios del cooperativismo, por ampliar el campo de acción de las sociedades y permitir su asociación en federaciones y confederaciones y, sobre todo, porque dejaba de tratar a las cooperativas como sociedades mercantiles por acciones sujetas a las disposiciones del Código de Comercio. 


\section{El proyecto cooperativo durante el cardenismo}

La ley de 1933 abrió la etapa de mayor crecimiento del cooperativismo, misma que se extendió a lo largo del cardenismo.

Hasta el 31 de diciembre de 1934 se habían constituido 778 cooperativas con 31,762 fundadores y un capital inicial de \$3’321,411.00 [...]. En sólo 19 meses de expedida la ley (junio de 1933 a diciembre de 1934) se organizaron 272 cooperativas con 7,780 fundadores, o sea un promedio de 14 cooperativas mensuales (Rojas-Coria, 1983, pp. 433-434).

El auge del movimiento no esperó, entonces, a la llegada del general Cárdenas a la Presidencia de la República. Si bien ese ascenso puede haber estado vinculado a su postulación por el PNR y a su inédita campaña electoral, cuando el presidente arribó a la cima del poder político las condiciones para su alianza con el sector cooperativo ya estaban en lo general dispuestas, tanto por las luchas que los cooperativistas habían venido librando en el terreno de la organización y el de su reconocimiento por los poderes públicos, como por la disposición de sus antecesores hacia el propio movimiento cooperativista.

Lo cierto es que, desde su campaña electoral, el joven general expresó su compromiso para con el cooperativismo. En un discurso del $1^{\circ}$ de mayo de 1934 manifestaba sin ambigüedades que:

El Plan Sexenal de nuestro instituto político, que establece en diversos de sus postulados la supremacía del sistema cooperativista, organizando socialmente a los trabajadores del campo y de la ciudad como productores y consumidores a la vez, irá transformando el régimen económico de la producción y distribuyendo la riqueza entre los que directamente la producen. Pero no se trata aquí del pseudocooperativismo burgués instituido entre nosotros desde las épocas de la Dictadura, sino de un cooperativismo genuino, constituido por trabajadores, dentro del cual puedan colaborar, sin excepción alguna, todos los elementos de trabajo y de consumo, hombres y mujeres, que deseen prestar su contingente para realizar la obra social de la Revolución, acabando así la explotación del hombre por el hombre; la esclavitud del hombre al maquinismo y sustituyéndola por la idea de la explotación de la tierra y de la fábrica en provecho del campesino y del obrero. Es de esperarse que mediante este sistema, técnicamente dirigido y ayudado económicamente por el Estado, juntamente con el movimiento sindicalista, y con un régimen adecuado de distribución, se logre una eficiente explotación de todas las riquezas naturales, para satisfacer e intensificar el consumo interior y aumentar nuestras exportaciones para la pronta liberación de nuestro crédito. Podrá objetarse que en algunos casos el sistema cooperativista no ha respondido a sus fines y ha producido resultados adversos; pero si analizamos serenamente estos fracasos, debemos convenir en que son de atribuirse a causas circunstanciales, como son: la poca preparación de los directores de las masas y aun la falta de disciplina de los miembros que las constituyen, más bien que a defectos del sistema y del fin económico en que se funda (Secretaría de Prensa y Propaganda del CEN del PNR, 1934, p. 50, citado en Córdova, 1974, pp. 76-77).

Y remataba su discurso manifestando su convicción personal por el cooperativismo:

[...] insisto constantemente en recomendar a hombres y mujeres de todo el país la unión; que dejen a un lado todos sus egoísmos, que sean liquidadas las divisiones, que estudien y experimenten el movimiento cooperativista, que nos ofrece fórmulas eficaces de lucha y de éxito para que se persuadan de las grandes ventajas que reporta la unión de los trabajadores, quienes con su doble carácter de productores y consumidores constituyen la médula de la economía nacional (citado en Rojas-Coria, 1983, p. 465).

Entre las muchas empresas cooperativas fundadas en el periodo cardenista, se destacan los Talleres Gráficos de la Nación, con los que se contrataban los impresos del Gobierno federal; la Sociedad Cooperativa de Obreros de Vestuario y Equipo, que abastecía al Ejército de uniformes militares, y los ingenios de Zacatepec, Morelos y El Mante, Tamaulipas, ambos entregados por el Gobierno a los trabajadores, a los que además refaccionaba bajo la figura de las cooperativas de participación estatal. Se trataba, en estos casos, de grandes empresas cooperativas que dependían fundamentalmente de la relación con el gobierno federal como consumidor o como abastecedor de insumos y créditos.

Otras muchas, en cambio, sí surgieron de esfuerzos de organización desde los grupos sociales involucrados en procesos productivos, como las cooperativas de ixtleros en el norte, las de tejedores de 
palma de la Mixteca o las de chicleros en Campeche y Quintana Roo. Incluso se formó, refiere Rojas-Coria (1983), una cooperativa de pepenadores ${ }^{1}$ en Ciudad de México, que introdujo el reciclaje de materiales de desecho y mejoró las condiciones de vida y de trabajo de sus socios. Además se reglamentaron las cooperativas escolares, y la Secretaría de Economía creó una escuela de cooperativismo por correspondencia -que en poco tiempo tenía 11 mil alumnos-y publicó la Revista de Cooperativismo.

El movimiento cooperativista, sin embargo, enfrentaba la acre oposición del movimiento sindical oficial, agrupado en la Confederación de Trabajadores de México (Стм), cuyo líder, Vicente Lombardo Toledano, veía en las cooperativas meros complementos del sistema capitalista, estériles para conducir a la emancipación de los trabajadores. Así, el dirigente cetemista afirmaba que:

La стм sustenta el principio de la lucha de clases, como la mayoría de las organizaciones de importancia en el mundo capitalista. En consecuencia, está en contra del sistema cooperativista como una solución del problema de la lucha de clases planteada: es la posición de los trabajadores frente al problema[...] los que consideran que el Estado debe intervenir para llegar a una sociedad más justa que la de hoy, no podrán pensar en una transición de la propiedad privada a la colectivización mediante esfuerzos de los particulares: sería absurdo[...] ¿Qué es el cooperativista en el mundo? Es un simple aliado de la gran producción capitalista. Creer que se puede remplazar la gran producción de la industria por la producción cooperativista de la misma industria, de manera pacífica, coadyuvando el sindicalismo con las huelgas, para que se cansen los propietarios o fracasen, y entregar los centros de trabajo a los obreros, para que éstos se organicen en cooperativas, es un error, una ilusión (Vicente Lombardo, 1938, citado en Córdova, 1974, pp. 77-78; la cursiva es añadida).

No obstante su distanciamiento del movimiento obrero, al concluir el sexenio cardenista el balance parecía ser más que alentador para el cooperativismo: se habían creado 937 cooperativas con 131739 integrantes, y en total existían 1715 asociaciones con 163 501 asociados que manejaban un capital total de 13 742 732,67 pesos (Rojas-Coria, 1983).

1 Recolectores de desperdicios sólidos como papel, cartón, botellas, latas, etc.
En 1935, se realizó en la capital del país el Segundo Congreso Nacional de Sociedades Cooperativas, auspiciado, como el primero, por el Gobierno de la República. Este reveló ya en sus acuerdos la tendencia creciente del movimiento cooperativista a establecer vínculos directos con el Estado, al punto que sus principales propuestas dependían casi enteramente de las políticas gubernamentales. No sólo se pedía la reforma de la Ley General de Cooperativa, sino también la creación de un banco cooperativo de crédito refaccionario con recursos del Estado; la introducción de la enseñanza del cooperativismo en la educación primaria, secundaria, técnica y comercial; la creación de un departamento autónomo de cooperativismo, dependiente del ejecutivo federal; la creación de una cooperativa de fianzas y garantías con capital del Estado; del establecimiento del seguro social cooperativo; la reforma de la Ley Electoral para implantar la representación proporcional de industrias, gremios y profesiones; el establecimiento en la Secretaría de Educación Pública (SEP) de un departamento de fomento cooperativo magisterial, escolar y de padres de familia; una academia de enseñanza técnica de cooperativismo, también a cargo de la SEP; la creación por esta de 500 plazas para profesores de cooperativismo distribuidos por el país; un proyecto para que el gobierno federal contratara los servicios públicos con las empresas cooperativas; y un proyecto para crear de una universidad cooperativa sostenida por el Estado (Rojas-Coria, 1983). Así, el programa entero del cooperativismo mexicano pasaba a depender de las políticas de Estado y de Gobierno.

La respuesta de este último no se hizo esperar. El presidente Cárdenas encargó en 1937 al licenciado Enrique Calderón la elaboración de un proyecto de ley de sociedades cooperativas, en tanto que la Liga Nacional Cooperativa (LNC) tenía el suyo, que se contraponía por entero al del Gobierno por los rasgos de autoritarismo que este acusaba. Mientras tanto, surgía un tercer proyecto elaborado por el diputado y general del Ejército Ramón F. Iturbe conjuntamente con el técnico Sealtiel Alatriste, de larga experiencia cooperativista.

Y pese a que la LNC y el diputado Iturbe unieron sus fuerzas para oponerse al proyecto oficial, este se impuso finalmente en lo general, incorporando tan sólo algunas modificaciones y adiciones. Su eje era conservar el control del mundo cooperativo en las manos del régimen a través de diversas vías. Y con frecuencia la justificación para ello era impedir que operaran como empresas cooperativas "aquellas 
organizaciones que sólo tienen el nombre de sociedades cooperativas, pero que en realidad constituyen organizaciones eminentemente capitalistas, verdaderas sociedades anónimas que utilizan elementos asalariados, convirtiéndose en explotadores del obrero" (Cárdenas, 1935, pp. 53).

Particularmente, la ley cardenista introducía un modelo único de organización que reglamentaba estrictamente los órganos internos de dirección de las organizaciones, el Consejo de Administración y el Consejo de Vigilancia (arts. 21-23), y debilitaba al primero prohibiendo la reelección de sus integrantes (art. 31); otorgaba el manejo de los fondos de reserva de las empresas cooperativas al Banco Nacional Obrero de Fomento Industrial (art. 43) ${ }^{2}$ y obligaba a todas ellas a contribuir para un Fondo Nacional de Crédito Cooperativo administrado por la misma institución (art. 45); establecía las figuras de las sociedades de intervención oficial y las sociedades de participación estatal (arts. 63-67); establecía también la afiliación obligatoria de las cooperativas a las federaciones y de estas a la Confederación Nacional Cooperativa (art. 72), y convertía a esta última en un órgano de planificación, conjuntamente con la Secretaría de la Economía Nacional, cuyos planes tenían que ser cumplidos por las federaciones (arts. 73 y 75), y otorgaba a esta dependencia amplias facultades para el control y la fiscalización de las sociedades cooperativas, desde su constitución y registro (art. 16) hasta la aplicación de sanciones penales a las asociaciones mismas o a los cooperativistas (arts. 8284; Rojas-Coria, 1983, pp. 476-491).

Es difícil saber hasta dónde, en este caso, un movimiento cooperativista controlado tan verticalmente desde el Estado fue realmente exitoso. Más allá de los impresionantes datos que hablan de su crecimiento cuantitativo, era la autenticidad del cooperativismo mismo, su autonomía frente al Estado y su pujanza efectiva lo que estaba en controversia. Si bien el presidente Cárdenas, refiriéndose a las cooperativas, a la administración obrera en los ferrocarriles y a la participación de los trabajadores en la industria

2 El Banco Nacional Obrero de Fomento Industrial tenía como objetivos esenciales los de "de otorgar un impulso decidido para la industrialización del país y el de conceder crédito a las empresas administradas por sus propios trabajadores y a las cooperativas. Para este efecto, se pond[rían] a disposición del Banco los recursos necesarios, entre los cuales figura[ban] las inversiones de Fomento industrial ya realizadas $[\ldots]$ a través del sistema de crédito popular, que se intensificar[ían] en lo sucesivo" (Cárdenas, 1937). petrolera recién expropiada, llegó a hablar de que se estaba creando un nuevo sistema, no capitalista, de economía nacional, la escasa capitalización de las empresas asociativas parece haberse convertido en su punto más débil. Las cooperativas de consumo no lograron competir ventajosamente con las tiendas privadas ni contribuir a mejorar los salarios reales, y en las cooperativas de producción:

Los obreros percibían menos salarios (anticipos) que en las empresas capitalistas, y eran frecuentes los casos de trabajadores que tenían que soportar varias semanas sin recibir un centavo. Además, casi en ninguna cooperativa los obreros disfrutaban del pago del séptimo día, ni de vacaciones ni de ninguno de los beneficios alcanzados por los sindicatos (Anguiano, 1975, p. 87).

En algunos casos, afirma este autor, los patronos entregaron las fábricas a los trabajadores, pero conservaron el control del abasto de materias primas, el crédito o la comercialización de la producción, con lo que convertían a las cooperativas en intermediarias o maquiladoras de sus negocios (Anguiano, 1975, p. 87).

Es algo difícil de determinar hasta dónde las cooperativas, sus dirigentes y los trabajadores asociados se dejaron llevar por el afán de lucro, y más cuando tales empresas eran el producto no tanto de luchas y de procesos de formación de conciencia obrera, sino de programas estatales de promoción y fomento con tintes socializantes. En ese espíritu de "aburguesamiento" - que solo puede haberse dado en el caso de las cooperativas económicamente exitosas-, sustentaba la Стм su crítica al cooperativismo, si bien esta confederación terminó por entrar también en consonancia con el gobierno cardenista y aceptando la integración de cooperativas de consumo y los casos "verdaderamente ineludibles" de cooperativas de producción (Anguiano, 1975).

\section{Cooperativismo y hegemonía}

No está en discusión el papel central que a las cooperativas, por derecho propio, les corresponde dentro de la economía social ni su potencial como uno de los factores para la reordenación de la economía y de la sociedad en la crisis estructural del sistema de producción capitalista, máxime en países donde, como en México, ese sector económico tiene antiguas y sólidas raíces comunitarias. 
No obstante, el análisis del cooperativismo en el periodo cardenista plantea no meramente el problema de la reorganización social y productiva, sino el de un proyecto de nueva hegemonía surgido de una revolución en la que los trabajadores no tuvieron la posibilidad de asumir la conducción ni de constituir la alianza dominante. Esa experiencia ilustra también los riesgos para un movimiento autónomo como el cooperativismo, cuando se subordina a dicho proyecto en aras de determinados beneficios económicos. En este caso, tal pacto de dominación se concretó en la Ley de Sociedades Cooperativas de 1938 y en la operatividad del corporativismo como uno de los basamentos del sistema político en su conjunto.

A lo largo de los 56 años de vigencia de esa ley cardenista - solo abrogada por la del gobierno de Carlos Salinas de Gortari en 1994-, Martínez-Ramírez y Rojas-Herrera (s. f.) destacan que se evidenciaron al menos los siguientes vicios:

a) Excesivo burocratismo en los organismos públicos de control y supervisión de las sociedades cooperativas; b) Participación de los partidos políticos en el movimiento cooperativo nacional con el objeto de generar las condiciones de contar el voto clientelar; c) Provocar el asistencialismo a la sociedad cooperativa por parte de los organismos públicos cooperativos; d) Irresponsabilidad y simulación en la creación de los organismos cooperativos de primer, segundo y tercer nivel, generándose la corrupción entre éstos y no cumpliendo sus objetivos fundamentales; e) La sociedad cooperativa se [convirtió] en una organización destinataria de políticas públicas equivocadas, sobre todo en lo que se refiere al apoyo financiero, generándose inversiones a fondo perdido y una corrupción escandalosa; f) La sociedad cooperativa, en 56 años, no representó una variable de desarrollo social y de influencia macroeconómica en el estado mexicano (p. 206).

El experimento de socialización de los años treinta, que combinaba en alguna escala, siempre insuficiente, el esquema cooperativo industrial con la colectivización ejidal y comunal en el campo, evolucionó muy pronto hacia un mero corporativismo obrero y campesino en el que el sector cooperativo asumía un lugar tan solo complementario al de las grandes centrales sindicales y, en el mercado, al de las empresas capitalistas privadas. En todo caso, un papel de gran pasividad frente al capital y el Estado, del cual dependía en mucho.
Un pequeño folleto titulado El cooperativismo y la clase obrera, editado en 1940 por la Secretaría de Economía, pretendía explicarles a los trabajadores las ventajas del sistema cooperativo desde una perspectiva fundamentalmente económica. Basándose en la teoría marxista de la explotación y de la reproducción del capital, su autor presentaba la raíz de la ganancia (lucro) capitalista y el permanente riesgo de la sobreproducción en este sistema. Explicaba cómo, en cambio, en la producción cooperativa esa explotación era suprimida cuando, además de recibir el productor asociado "una remuneración" igual al salario de los obreros, al final del ciclo, al venderse las mercancías, la plusvalía obtenida $d$, "que tiene el mismo valor del $d$ resultante del proceso capitalista, es dividid[a] entre los socios de la cooperativa en proporción a las horas que cada uno de ellos ha trabajado". Esto significa que "no existirá más explotación de la fuerza de trabajo, ft, y que, por lo tanto, cada obrero recibirá integro el valor de su esfuerzo, ya que verá remuneradas todas sus horas de trabajo". La conclusión no podía ser sino que "la cooperación de producción libra a la fuerza de trabajo de la explotación capitalista" (Frola, 1940, pp. 20-21).

Ese modesto y pedagógico folleto cardenista presenta con nitidez los riesgos del cooperativismo. Uno de ellos es que, al sustituir la figura del salario por la de las participaciones en la ganancia operada en un mercado esencial y generalmente capitalista, aquel tiende a disociarse de la condición del resto de la clase trabajadora, ubicándose en una posición intermedia y ambigua entre la del obrero - en cuanto productor directo - y la del capitalista - en cuanto copropietario y administrador de sus medios de producción-. Esa posición es la que ha permitido a sus críticos hablar del aburguesamiento de los cooperativistas. Pero el cooperativismo también contiene en sí el embrión para una sociedad autodeterminada de productores directos organizados como la pensada por Marx. Esa potencialidad, como es sabido, puede limitarse solo a las relaciones internas de la empresa cooperativa o extenderse al conjunto de la economía, constituyéndose en una alternativa al sistema de producción y distribución capitalista.

Otro riesgo consiste en que analizar tan sólo las relaciones internas de la empresa cooperativa lleve a perder de vista el contexto esencialmente capitalista del mercado. La distribución equitativa de la ganancia ("lucro" en términos del autor) entre los cooperativistas no elimina las relaciones de explotación para el conjunto de los productores directos. Se ven los árboles, mas no el bosque. 
En ninguna de estas dos situaciones el cooperativismo avanza en el despliegue de su potencial solidarista y de proyección social ni en su capacidad pedagógica para desarrollar en el individuo, de manera práctica, una conciencia crítica frente a las relaciones de explotación.

Por otra parte, la relación cooperativas-Estado en la etapa cardenista y en las que le siguieron no implicó una posición meramente pasiva de aquellas frente al poder público. Este no fue un mero instrumento de represión en manos de la clase dominante, sino el resultado de un conjunto de prácticas sociales que condujeron a la construcción de formas específicas de hegemonía y, por tanto, de consenso de las clases y los grupos dominados. Entre tales prácticas, se ubica la conformación de alianzas con estas clases y grupos sociales en un proceso dinámico que permitiera la modernización y el avance de las relaciones de producción y de la sociedad en su conjunto. El hecho de que el sector cooperativo se conformara de manera autónoma como un movimiento independiente del Estado y de la clase dominante, o se integrara como una parte del sistema de alianzas que permitió a la postre consolidar el pacto de dominación y hegemonía capitalista en el país - es decir, constituirse en parte del Estado ampliado, en el sentido de Gramsci (1975) - se determinó en la dinámica de las mismas clases sociales y de la correlación de fuerzas entre ellas. Al igual que el movimiento sindical, el cooperativo llevó muy lejos su alianza con el Estado y conformó una burocracia semejante a la de aquel y en consonancia con el aparato administrativo del Estado, que frenó su desarrollo como alternativa autónoma ante el poder político.

Hoy, la crisis del proyecto desarrollista estatal y del Estado benefactor, pero también la de la reestructuración oligárquico-neoliberal, ubican al movimiento cooperativista en una situación muy distinta de la que vivió en los años treinta. Dentro del proyecto de dominación y hegemonía oligárquico-financiera actual, en el bloque de poder no hay cabida para incorporar a las clases y sectores subalternos. Las condiciones de tal esquema de poder económico y político rompieron con el dilema del cooperativismo en la etapa del desarrollismo, que lo conducía al dilema de la dependencia estatal o de la marginalidad social y la esterilidad de acción, y colocaron al movimiento cooperativo en condiciones de mayor beligerancia frente a la dominación capitalista. La actual crisis moral y económica del orden inspirado en el neoliberalismo abre así nuevas perspectivas al cooperativismo y al conjunto del movimiento obrero.
Por ello, aun dentro del contexto feroz en el que la economía se ha desarrollado a lo largo de las últimas décadas, algunas experiencias cooperativas han logrado subsistir y aun crecer en determinados momentos, aprovechando sus ventajas en el mercado, pero sin abandonar los principios sociales y de solidaridad, en sus mejores expresiones, del movimiento cooperativo. La Cooperativa de Refrescos Pascual, la Sociedad Cooperativa Trabajadores Democráticos de Occidente (Tradoc, en la rama llantera), la Sociedad Cooperativa de Compra y Venta en Común "El Grullo", Yomol A'tel (productores de café en Chiapas), la Unión de Cooperativas de Tacámbaro, Michoacán, entre otras, son algunos ejemplos de economía social y solidaria que se han formado en distintas circunstancias o han logrado subsistir aun en medio de la devastación económica y del estancamiento que la reestructuración oligárquico-neoliberal ha producido en México en las últimas décadas.

En un texto del 2009, el académico costarricense Miguel Sobrado reflexionó ampliamente acerca de lo que él llama la "oportunidad histórica del cooperativismo". La misión histórica de este no puede ser solo integrarse eficientemente a las esferas de la producción y la distribución sino:

Contribuir a la formación de la nueva clase dirigente en el continente [a través de] destacamentos bien formados capaces de impulsar las formas asociativas locales y regionales y promover activamente la adecuación de las políticas sociales a la generación de empleo y reducción de la pobreza.

La condición para ello es que el movimiento cooperativista abandone sus posiciones tradicionalmente apolíticas y se comprometa con proyectos de transformación social, participando en los procesos de toma de decisiones pero conservando siempre su autonomía frente a los partidos políticos. Tanto la experiencia histórica como las bases sociales ya existentes convergen con el nuevo avance de la democracia participativa, conspirando en esa tarea de gestar una nueva hegemonía capaz de contribuir a la superación de la desigualdad y la exclusión. Una utopía, aparentemente; pero de esas que, como dice Eduardo Galeano, sirven para avanzar.

\section{Conclusiones}

La experiencia del movimiento cooperativista en el cardenismo muestra la necesidad de contextualizar social e históricamente su acción para trazar sus 
objetivos y estrategias en cada periodo. Se trató en ese caso de una etapa de gran desarrollo numérico de las empresas cooperativas y de sus integrantes, pero en el cual el crecimiento mismo y sus condiciones de existencia dependieron en gran medida de la intervención de un gobierno comprometido con un proyecto de socialismo estatal, surgido de la Revolución mexicana. Así, el movimiento cooperativista quedó integrado dentro de ese proyecto, más que constituir una expresión de autonomía de los productores directos. El rechazo de las expresiones más fuertes del movimiento sindical al cooperativismo completó un cuadro en el que a este le era virtualmente inevitable compartir el proyecto desarrollista gubernamental.

El cooperativismo mexicano durante los años veinte y treinta del siglo $\mathrm{xx}$, en la etapa inmediata a la Revolución, pone en evidencia cómo la obtención de ventajas y avances inmediatos puede, sin embargo, representar un pacto de compromiso inconveniente a la larga para la autonomía del movimiento cooperativista, sobre todo si ese desarrollismo llega a su fin.

Es una experiencia que puede iluminar los dilemas del movimiento con el fin de evitar su repetición. Hoy, ante la desaparición histórica del desarrollismo y el inminente agotamiento del capitalismo neoliberal, el movimiento cooperativista - cuyo otro dilema es el economicismo implicado en su adaptación al productivismo y a las condiciones del mercado-, debe reflexionar acerca de su posible incorporación al proceso de construcción de su propia autonomía y la de otros sectores de la clase trabajadora. Solo así se podría impulsar una transformación más radical de la economía y de las relaciones sociales. En última instancia, no se trata solo de modificar las relaciones de producción en la unidad de producción ni de distribuir hacia los cooperativistas, en ausencia de un propietario privado, la ganancia media generada en el mercado capitalista, sino de contribuir a la disipación de las relaciones de explotación en el conjunto de la sociedad. En última instancia, de construir un nuevo proyecto de hegemonía que, frente a la crisis del estatismo y la del capitalismo liberal a ultranza de nuestros días, traslade aquella de manos de los grupos propietarios a las de los sectores laborantes, asalariados o no.

\section{Referencias}

Anguiano, A. (1975). El Estado y la política obrera del cardenismo. México: Ediciones Era.

Cárdenas, L. (1935). I Informe de Gobierno del Presidente Constitucional de los Estados Unidos Mexicanos. $1^{\circ}$ de septiembre de 1935. En L. Cárdenas, Palabras y documentos públicos de... Vol. 2: Informes de gobierno y mensajes presidenciales de año nuevo 1928/1940. México: Siglo XXI.

Cárdenas, L. (1937). III Informe de Gobierno del Presidente Constitucional de los Estados Unidos Mexicanos. $1^{\circ} \mathrm{de}$ septiembre de 1937. En Diario de los debates de la Cámara de Diputados del Congreso de los Estados Unidos Mexicanos. xxxvir Legislatura, Año I, Tomo I, núm. 7.

Contreras, M. y Tamayo, J. (1983). Antología México en el siglo Xx, 1900-1913. Vol. 2: Textos y documentos. MéXico: UNAM.

Córdova, A. (1974). La política de masas del cardenismo. México: Ediciones Era.

Frola, F. (1940). El cooperativismo y la clase obrera. México: Secretaría de la Economía Nacional.

Gramsci, A. (1975). Notas sobre Maquiavelo, sobre política y sobre el Estado. México: Juan Pablos Editor.

Martínez-Ramírez J. y Rojas-Herrera J. (2003). Panorama del sector cooperativo mexicano. Unircoop. Recuperado de http://www.unircoop.org/unircoop/files/bibliotheque/vol1no2\%5B1\%5D.11.unircoop.mexique. pdf(1).pdf

Rojas-Coria, R. (1984). Tratado de cooperativismo mexicano (3a ed.). México: Fondo de Cultura Económica.

Sobrado, M. (2009). La oportunidad histórica del cooperativismo. Ponencia presentada en la I Cumbre Cooperativa de las Américas. Guadalajara, Jalisco, México, 21-25 de septiembre de 2009. Recuperado de http://www. aciamericas.coop/IMG/pdf/Miguel_Sobrado-Cumbre_Mexico_eje_3.pdf 